\title{
Adolescentes E Jovens Com Alergia Alimentar: Percepções Sobre O Bullying
}

\author{
Adolescents and Youth With Food Allergies: Perceptions of \\ Bullying
}

DOI: $10.54019 / \operatorname{sesv3n1-016}$

Recebimento dos originais: 01/1/2021

Aceitação para publicação: 31/01/2021

\begin{abstract}
Patrícia de Moura Vieira
Pedagoga, graduada pela Universidade Federal do Paraná (UFPR), especialista em Psicopedagogia pelo Centro Universitário Curitiba, especialista em Educação Especial Inclusiva e em Arte Educação e Terapia pela Faculdade São Braz.

E-mail: patytessari@yahoo.com.br
\end{abstract}

\section{RESUMO}

O objetivo deste artigo consiste em discorrer sobre a alergia alimentar e sua relação com o bullying entre jovens no ambiente escolar, visto que o Brasil carece de pesquisas que relacionam os dois temas. Apuraram-se aspectos da convivência escolar ética em contraposição ao bullying, com o intuito de trazer um olhar para possíveis vítimas em potencial. Constatou-se que o clima escolar influencia diretamente na qualidade do aprendizado e na diminuição dos conflitos entre pares. Estudos internacionais apontam que alunos com alergia alimentar têm sido alvos de bullying no ambiente escolar e há um aumento dessa incidência nos últimos anos. As alergias alimentares podem trazer não só desconforto em aspectos físicos, mas também psicológicos, principalmente na escola, que é um ambiente de interação e convivência. O bullying tem um impacto emocional significativo em um indivíduo que já está fragilizado pela sua condição de saúde. Portanto, é preciso buscar a conscientização sobre as alergias alimentares e o bullying. Promover a formação moral dos nossos jovens, baseada nas relações sociais cooperativas, solidárias e não excludentes através do diálogo.

Palavras-chave: Bullying, Alergia alimentar, Convivência escolar.

\section{ABSTRACT}

The objective of this article is to discuss about food allergy and its relation with bullying among youngsters in school environment, since Brazil lacks researches that relate both themes. Aspects of ethical school coexistence as opposed to bullying were investigated, with the intention of bringing a look at possible potential victims. It was found that the school climate directly influences the quality of learning and the reduction of conflicts among peers. International studies point out that students with food allergies have been targets of bullying in the school environment, and there has been an increase in this incidence in recent years. Food allergies can bring not only physical discomfort, but also psychological discomfort, especially at school, which is an environment of interaction and coexistence. Bullying has a significant emotional impact on an individual who is 
already weakened by his health condition. Therefore, we must seek to raise awareness about food allergies and bullying. To promote the moral formation of our young people, based on cooperative, supportive, and non-exclusive social relationships through dialogue.

Keywords: Bullying, Food Allergy, School Coexistence.

\section{INTRODUÇÃO}

Embora desconhecidas de muitas pessoas, as alergias alimentares acometem uma parcela cada vez maior da população, como adolescentes e jovens (SANTOS, 2017; PINHEIRO, 2020). Podem trazer desconforto, vulnerabilidades e exclusão, principalmente no ambiente escolar, podendo afetar o desempenho em aspectos físicos, cognitivos, afetivos e sociomorais (PINHEIRO, 2020), e, ainda, implicações psicológicas e bullying (CABRAL, 2019). O diagnóstico de alergia alimentar pode ter um impacto significativo sobre 0 indivíduo e sua família, incluindo restrições às atividades familiares e de socialização, associados a um alto nível de angústia e preocupação nos pais sobre a condição da criança (FONG et al., 2017). A percepção sobre a qualidade das relações interpessoais de adolescentes e jovens que sofrem com algum tipo de restrição alimentar é de fundamental importância na busca de uma educação de qualidade que promova o pleno desenvolvimento do educando, com consequente contribuição para a formação de cidadãos justos e honestos, com valores morais que possam contribuir para uma sociedade menos excludente.

Nesse sentido, é preciso entender os processos de convivência no ambiente escolar, principalmente por alunos que são acometidos com algum tipo de alergia proveniente da ingestão de alimentos (ANDRADE, 2020). Situações conflituosas refletem diretamente na qualidade do clima escolar, afetando, por sua vez, o rendimento e o desempenho dos estudantes, levando às situações de violência, indisciplina, bullying (VINHA, 2016) que aparecem como uma das maiores dificuldades enfrentadas pelas escolas (VINHA et al., 2017). Frente a isso, é necessário buscar estratégias para melhorar a convivência dentro da escola, promover relações sociais cooperativas, solidárias e não excludentes entre adolescentes e jovens, bem como, buscar uma convivência ética e baseada em valores. Pesquisas internacionais evidenciam que estudantes com alergia 
alimentar sofrem bullying (BECKER, 2013; DIAS, 2016; FENG, 2018; FONG et al., 2017; LIEBERMAN, 2010; LIN, 2014; MURARO et al., 2014; SHEMESH et al., 2013).

Assim, este artigo tem por objetivo discorrer sobre a alergia alimentar e sua relação com o bullying entre adolescentes e jovens. Para isso, busca aporte na Psicologia e Moralidade para abordar aspectos da convivência escolar ética em contraposição às situações de violência escolar, como o bullying. Por fim, traz elementos em relação à alergia alimentar e tece considerações sobre a relação entre a incidência do bullying escolar motivado por estigmas relacionados à alergia alimentar.

\section{CONVIVÊNCIA ESCOLAR}

Estudiosos apontam que é importante adotarmos o espaço escolar não apenas como um lugar onde se ensinam conhecimentos e se transmite conteúdos, mas também, em um lugar onde se aprende a viver com os outros e a respeitá-Ios (SERRANO, 2002 apud ZECHI, 2014). A escola deve fomentar a sensibilidade ética, estimular a convivência sadia entre os alunos através de relacionamentos pautados em valores e não apenas ser um local onde se transmite normas e regras rígidas ou princípios de conduta. $\mathrm{Na}$ escola tem se a educação secundária, que consiste no ensino dos conhecimentos e na aprendizagem dos valores sociais, que é a convivência democrática por excelência (VINHA, 2018). Autores relacionam a qualidade do clima escolar com a qualidade do aprendizado e na diminuição dos conflitos entre pares, pautados na boa convivência no ambiente escolar, pois, "a boa qualidade do clima relacional é resultante das relações positivas que ocorrem nesse espaço, das oportunidades de participação efetiva, da garantia do bem-estar, respeito e apoio entre as pessoas, promovendo continuamente o sentimento de pertencimento" (MORO et al., 2019, p. 9).

Para Zechi (2014), a escola é um espaço privilegiado para a promoção da formação moral e ética entre os alunos, assim como, para a manutenção ou mudança de valores. Segundo a teoria de Piaget (1932-1994), a construção de valores morais pelo indivíduo acontece junto ao desenvolvimento cognitivo, social e afetivo, nos diversos ambientes de interação, como a família e escola. Então, 
ao proporcionar a convivência diária entre crianças e jovens, ao transmitir valores, a escola assume um papel importante na construção desses princípios norteadores da convivência, cabendo a ela educar os indivíduos enquanto sujeitos morais e éticos para a vida em comunidade. É importante que reconheçamos que vivemos hoje em uma mudança de valores, assim, não devemos pensar numa formação moral e ética que preze por valores inexistentes, mas discutir os valores que os alunos trazem, Do contrário, a escola se tornaria um ambiente de imposição de valores, ou seja, autoritária (ZECHI, 2014).

Estudos de Menin et al. (2017) apontam a importância da educação em valores sociomorais ou educação para a ética, que segundo ela, é uma educação que tenha como objetivo a consolidação, construção e prática de princípios, valores, normas e regras, assumidos de uma maneira autônoma pelas pessoas, com o objetivo de orientá-los a viver de maneira harmônica, consigo mesma e com os demais, no que culturalmente se considera como bom, justo e correto. A assimilação desse conceito pela escola, aqui se referindo aos agentes escolares como professores, direção e setor pedagógico, parte do princípio da internalização por parte destes e práticas de métodos de ensino que busquem consolidar os objetivos de uma educação para a ética. Como reforçam Menin et al. (2017), a escola deve imbuir-se de educar moralmente seus alunos e fazê-lo de forma intencional e planejada. Ou seja, uma educação integral de seus alunos, pois a escola é um dos principais espaços sociais para a educação moral.

Bozza (2016), dissertando sobre a família e a escola contemporânea, indica que a família tem seu papel de socialização, proteção e estabelecimentos de vínculos. Já a escola é o lugar onde a criança encontrará estabilidade para transformar valores particulares em socialmente desejáveis (ou não). Por conseguinte, a escola também possui papel socializador, ainda que secundário. De acordo com a autora, é na escola que as crianças e adolescentes têm a oportunidade de vivenciar o coletivo, estabelecer relações com seus pares, perceber a necessidades de regras, preocupar-se com o bem comum e perceber que a qualidade das relações interpessoais depende de todos os envolvidos. $O$ ensino da convivência, então, recai sobre o professor, visto que [...] "alguém tem de ensinar os sujeitos a respeitarem a todos no mundo. Esse respeito só se aprende na escola" (BOZZA, 2016, p. 32). 
O grande papel atual da escola é formar o ser humano em sua totalidade, não só as habilidades cognitivas, mas também morais, sociais e afetivas, sendo por excelência, um ambiente de convivência e socialização (BOZZA, 2016). Porém, a autora ressalta que a escola de hoje está mais preocupada em manter a ordem e a obediência, do que aos problemas afetivos e à qualidade das relações interpessoais dos alunos, deixando de lado a contribuição na formação ética dos mesmos. Isso pode justificar o aumento dos casos de violência, situações de indisciplina e de desrespeito no ambiente escolar.

Com o intuito de compreendermos melhor a influência de um ambiente mais ético conceitua-se convivência ética.

A ética é um conjunto de saberes relacionado ao estudo das regras morais, as quais fundamentam o comportamento do ser humano. La Taille (2010) indica que para ser uma pessoa ética é preciso agir de acordo com um comportamento moral. Em outras palavras, ética é uma perspectiva adotada pelo indivíduo com base em seus conhecimentos sobre o agir moral. "[...] o sujeito moral sente-se intimamente obrigado a agir segundo determinadas regras, valores e princípios" (LA TAILLE, 2010, p. 2). Portanto, uma convivência ética é aquela pautada em valores morais, respeito mútuo, empatia pelo outro, que preza por sentimentos de justiça, igualdade, solidariedade e cooperação, ou seja, por formas mais justas e adequadas de convivência.

De acordo com Zechi (2014), na atualidade há um debate se estamos passando por uma "crise de valores", representada pela ausência ou falência dos valores tradicionalmente aceitos pela sociedade. Isso fragiliza o debate entorno de uma educação voltada para a formação moral e ética, descredibilizando a escola quanto à possibilidade de ainda conseguir cumprir essa função. Segundo a autora, baseada em estudos de La Taille e Menin (2009), há uma reflexão se é uma "crise de valores" ou "valores em crise", caracterizado pela reinterpretação dos valores existentes, rearranjo moral e criação de novos valores, novas inquietações éticas, mais importantes para a geração atual. Nessa perspectiva é importante que pensemos na melhoria da convivência escolar pautada em valores morais. 


\section{QUAL A IMPORTÂNCIA DE PROMOVER RELAÇÕES SOCIAIS} COOPERATIVAS, SOLIDÁRIAS E NÃO EXCLUDENTES ENTRE ADOLESCENTES E JOVENS?

Para Araújo (2001), um ambiente escolar cooperativo é aquele onde a opressão do adulto é mínima e onde se criam condições que favoreçam a cooperação, o respeito mútuo, as atividades grupais que favoreçam a reciprocidade, a ausência de sanções expiatórias e de recompensas, e onde as crianças tenham oportunidades de fazer escolhas, tomar decisões e de expressarse livremente. Para o autor, a cooperação é uma relação entre indivíduos que se consideram como iguais, uma relação social na qual não há autoridades ou prestígios envolvidos. Para que surjam relações de cooperação é necessária uma convivência cada vez maior com crianças da mesma idade, proporcionando trocas sociais e cognitivas mais intensas, colocando seus pontos de vistas em reciprocidade e considerando o ponto de vista do outro (ARAÚJO, 2001).

Nesse sentido, percebemos a importância de construir um ambiente cooperativo e vivenciar os jovens com situações que gerem reciprocidade e empatia. A escola, segundo Araújo (2001), tem papel fundamental, pois tem responsabilidade na construção de personalidades morais, como uma instituição responsável pela democratização do acesso aos conteúdos e o desenvolvimento individual de seus membros, trabalhando as capacidades cooperativas ao mesmo tempo em que respeita as diversidades das crianças, inserindo assim, cidadãos autônomos e conscientes em uma sociedade plural e democrática. O autor também salienta que, em um ambiente escolar onde os sujeitos têm a oportunidade de expor suas ideias, condutas e sentimentos em reciprocidade com os demais, os alunos exercitam a sua cognição em situações verdadeiras do cotidiano, com isso, há uma melhora em suas relações interpessoais.

Considerando este contexto de convivência ampla, é preciso um olhar para estudantes com restrição alimentar. Por vivenciarem uma condição diferente de alimentação, podem ser alvo de bullying de seus pares (BECKER, 2013; DIAS, 2016; FENG, 2018; FONG et al., 2017; LIEBERMAN, 2010; LIN, 2014; MURARO et al., 2014; SHEMESH et al., 2013). 


\section{BULLYING ESCOLAR}

De acordo com Frick (2019), o bullying não se restringe somente ao ambiente escolar e à área de educação, mas é nesta área que se dá maior atenção a ele. A conceituação de bullying deve levar em conta a complexidade do fenômeno que é [...] "uma forma perversa de relação interpessoal que ocorre no seio de um grupo" (FRICK, 2019 p.11), envolvendo os autores (quem comete as agressões ou insultos, geralmente estão em grupo), as vítimas (que são os alvos das agressões) e os espectadores, que dão palco para os autores, assistindo o cometimento das agressões. O bullying deve ser entendido de maneira mais ampla, como um fenômeno que acontece por meio de agressões intencionais e com certa frequência contra um alvo que está em desvantagem, ou seja, o desequilíbrio de poder em relação à vítima (STELKO-PEREIRA, 2010) é um fator presente nestas situações (FRICK, 2019). A expressão bullying corresponde a um conjunto de atitudes de violência física e/ou psicológica, sociais e verbais (TOGNETTA, 2008) de caráter intencional e repetitivo, contra uma ou mais vítimas que se encontram impossibilitadas de se defender (SILVA, 2010).

O termo bullying se refere às condutas de intimidação, tiranização, isolamento, ameaças e insultos a uma ou mais pessoas, e sua ocorrência não é somente entre pares, podendo ser entre crianças e adolescentes, pais e filhos, alunos e professores, chefe e subordinado (FRICK, 2019). No entanto, há pesquisadores no Brasil que usam outros termos para definir as violências que ocorrem envolvendo uma relação com autoridade instituída (STELKO-PEREIRA, 2010; TOGNETTA et al., 2014). Termos como "armar-se”, "insulto”, "provocação”, "rejeição", e "violência" foram usados para definir bullying (SMITH et al., 2002), bem como, "violência entre pares" e "intimidação por pares" (STELKO-PEREIRA, 2010).

A intencionalidade é o desejo de produzir o dano em outra pessoa, o autor comete bullying com a intenção clara de prejudicar a outra pessoa. A repetição, que é provável que aconteça, mas que não é uma exigência, apenas diferenciará a casualidade de uma ação rotineira, evidenciando que o bullying foi direcionado a um alvo pré-determinado. Outro critério é o desequilíbrio de poder. Este precisa ser analisado do ponto de vista do alvo, o qual se sente incapaz de defender-se, relacionado a fatores como a confiança, a popularidade, o status no grupo (FRICK, 
2019). Essa percepção de incapacidade pode ser a chave para o desequilíbrio de poder, pois o alvo de bullying pode ser mais fraco ou sentir-se assim (OLWEUS, 2013). É como se o alvo, ao ser considerado mais fraco, concordasse com essa posição de desvantagem onde o autor o coloca. Mesmo que tente sair dessa posição, não consegue tomar ciência e superar seus próprios medos e desafios.

O bullying é um fenômeno complexo e não se pode apontar como possíveis causas, fatores como ser aluno novo na classe; ter temperamento impulsivo; tratar como sendo algo natural; tratar apenas como sendo desvio de comportamento ou indisciplina; ou apenas como brincadeira da idade (FRICK, 2019). Há uma complexidade de fatores que influenciam nas relações entre os adolescentes, e o bullying deve ser entendido como fenômeno de grupo, em que os autores, na busca por status, visibilidade, popularidade, prestígio social, praticam proativamente agressões contra uma ou mais pessoas e não se sentem mal com isso, principalmente quando várias pessoas participam da ação como espectadores (FRICK, 2019).

Ainda com relação às causas do bullying, outros fatores foram estudados, como o desequilíbrio emocional dos alvos, mas o que fica mais latente é que o bullying é um problema moral ou de sua falta (TOGNETTA, 2013), visto que há uma ausência de valores morais como justiça e respeito nas ações. O desengajamento moral de quem pratica o bullying é evidente em situações em que o respeito ao outro está em jogo (FRICK, 2019; TOGNETTA, 2013).

O bullying traz inúmeros prejuízos às pessoas envolvidas, não só as vítimas, mas também os autores e espectadores necessitam de ajuda, pois a prática do bullying incide diretamente na qualidade das relações interpessoais na escola (TOGNETTA, 2008). As consequências são nefastas para as vítimas, que desenvolvem desde problemas de ansiedade, depressão, solidão, insegurança, baixa confiança social, pânico da escola, prejuízos com o rendimento escolar, medo, até mesmo levando ao suicídio. Já os autores desta violência devem ser ajudados no sentido de desenvolver sensibilidade moral perante o sofrimento do outro, deslegitimar a agressão, a injustiça, o uso abusivo do poder (FRICK, 2019).

Em relação aos espectadores, alunos que assistem as agressões, também podem desenvolver ansiedade, medo de ser a próxima vítima e até culpa por não conseguir ajudar alguém que esteja sofrendo bullying (FRICK, 2019). As 
consequências deste fenômeno vão além dos muros da escola, envolvendo também às famílias, por isso é importante que os pais encontrem acolhimento na escola quando buscarem ajuda, lidando com a situação de maneira conjunta (FRICK, 2019).

\section{ALERGIA ALIMENTAR}

Nas últimas décadas observou-se um aumento significativo de crianças com doenças alérgicas relacionada aos alimentos, esse fato ocorre devido à exposição precoce aos alérgenos na dieta, por não haver aleitamento materno exclusivo até os 8 meses de vida (SABRA, 2015). As reações, na maior parte dos casos, aparecem logo após a ingestão dos alimentos. A restrição aos alimentos causadores das alergias é essencial para que a criança possa ter qualidade de vida. Portanto, crianças com alergia alimentar, tem restrição a certos alimentos e não podem ingeri-los.

Segundo Sarinho (2017), alergia alimentar é uma resposta imunológica anormal do organismo a um determinado alimento, podendo levar a síndromes clínicas com risco à vida. Essa síndrome acontece a cada vez que o alimento é ingerido e pode levar a anafilaxia induzida pelo alimento. Anafilaxia é uma reação grave ao alimento, em que ocorre vasodilatação generalizada, sendo acompanhada de hipotensão e hipoperfusão, comprometendo órgãos como cérebro e coração, podendo levar a morte. O autor também aponta que houve um aumento sucessivo dos casos de alergia alimentar, principalmente a forma mais grave, a ponto de ser a principal causa de atendimentos nas emergências por anafilaxia em alguns países, no Brasil é apontado como a segunda causa de anafilaxia.

A ASBAI (Associação Brasileira de Alergia Alimentar) conceitua alergia alimentar como sendo uma reação adversa a determinado alimento, envolvendo um mecanismo imunológico, com sintomas que podem aparecer na pele, no sistema gastrintestinal e respiratório. Com reações leves como coceiras, até reações mais graves envolvendo vários órgãos (ASBAI, 2019). É a resposta exagerada do corpo humano a uma determinada substância que está presente no alimento. Reações alérgicas a alguns alimentos são comuns em todo mundo e acometem de 2 a $4 \%$ da população adulta e 6 a $8 \%$ das crianças menores de três 
anos de idade (SAMPSON, 2006). No Brasil, os dados sobre prevalência de alergia alimentar são escassos, o que dificulta uma avaliação mais precisa (ASBAI, 2018). Silva et al (2017), realizaram estudos parar avaliar a prevalência de alergia alimentar entre adultos brasileiros (18-65), com taxa de sintomas referidos de 10,8\% e diagnósticos médicos de 1,0\%.

Os principais alimentos causadores de alergias são: leite de vaca, ovos, amendoim, castanha, nozes, trigo (doença celíaca), gergelim, soja, crustáceos, peixes e algumas frutas. Nas crianças pré-escolares, leite de vaca e clara de ovo estão entre os alimentos que mais causam alergias. Os estudantes com necessidades alimentares especiais são aqueles que possuem alergias alimentares, diabetes, intolerância à lactose, doença celíaca ou outra condição que possa demandar alimentação escolar diferenciada (FNDE, 2016).

Com relação à doença celíaca, esta é uma doença crônica caracterizada pela inflamação no intestino delgado pela ingestão do glúten presente no trigo, aveia, cevada e no centeio (alimentos presentes na maior parte da dieta das escolas, como pães, macarrão ou bolachas), e afeta cerca de $1 \%$ da população na maioria dos países, (SEVINÇ, 2017). Em estudo realizado em crianças com idade escolar na Turquia, e que sofriam com a doença celíaca, foram detectados prejuízos na qualidade de vida ao diminuir a funcionalidade nas relações sociais, na vida emocional e na saúde física. No mesmo estudo foi identificado que alunos com doença celíaca sofriam com depressão (23\%), transtorno de ansiedade (22\%), e dificuldade de adaptação (15\%), levando a um estresse psicossocial, isolamento e estigmatização (SEVINÇ, 2017).

\section{ALERGIA ALIMENTAR E BULLYING}

Em pesquisa realizada por Santos (2017), observou-se que as reações adversas aos alimentos não implicam apenas na segurança alimentar, mas também nos relacionamentos dos alunos. No estudo foi possível detectar que os impactos nas relações sociais foram mais perceptíveis do que as próprias restrições. A ignorância em relação ao tema "alergias alimentares" demostra ser um fator que colabora com o menosprezo daquele que já se encontra fragilizado pela situação de alimentação restrita, gerando preconceito, falta de respeito e 
bullying. Ficando clara a urgente necessidade de conscientização sobre o tema (SANTOS, 2017).

Alguns relatos observados na pesquisa de Santos (2017) dão conta de que uma determinada escola pública condicionou a matricular um aluno, desde que a mãe autorizasse a mesma a permitir que, na hora do lanche, o aluno fosse isolado na classe até que o restante da turma se alimentasse. Esta ação, na tentativa de salvaguardar a segurança alimentar, poderia colocar esse aluno em evidência perante os demais, podendo fomentar uma situação de bullying. Também foram observadas outras situações em que a escola exigiu que o aluno trouxesse seu próprio lanche, também desrespeitando o direito ao alimento adequado.

Nos Estados Unidos, um estudo realizado por Lieberman et al. (2010) com 353 pacientes com alergia alimentar, em que 67,5\% tinham idade escolar (4-18 anos), $24 \%$ dos entrevistados relataram ter sofrido bullying por causa da alergia alimentar. Não obstante, dos que foram intimidados, $86 \%$ relataram que os episódios foram constantes, $82 \%$ dos episódios ocorreram na escola e $80 \%$ perpetrados por colegas de classe. O que mais surpreendeu foi que $21 \%$ dos casos de bullying por alergia alimentar vieram de professores e outros funcionários da escola. Houve uma variação nos motivos do bullying, como ser vítima de bullying simplesmente por causa de sua alergia alimentar, ter que carregar ou usar medicamentos, ou trazer seu próprio alimento, comer separado dos demais ou recebendo tratamento especial. Alguns entrevistados relataram principalmente tristeza, depressão, constrangimento ou humilhação como resultado do bullying.

Em estudos realizados por Shemesh et al. (2013), nos Estados Unidos, foram observados que $30 \%$ dos respondentes relataram que o bullying é comum entre os pacientes com alergia alimentar, associado a menor qualidade de vida, $45,4 \%$ das crianças relataram ter sido intimidadas ou assediadas por qualquer razão, sendo $31,5 \%$ especificamente pela alergia alimentar.

Lin e Sharma (2014) realizaram um estudo sobre provocação e bullying com 115 adolescentes entre 11 e 22 anos, dos Estados Unidos e Canadá, com alergia alimentar, em que $71 \%$ dos entrevistados relataram terem sido provocados por outras crianças por causa de sua alergia alimentar. 
Em estudos realizados na Itália por Muraro et al. (2014), comparando 120 pacientes com alergia alimentar e 120 pacientes não alérgicos, entre 8 e 19 anos, foi identificado que, $60 \%$ dos entrevistados com alergia alimentar relataram ter sofrido alguma forma de bullying nos últimos 2 meses contra $31,7 \%$ dos não alérgicos, chegando à conclusão que os jovens que acometidos por alguma alergia alimentar possuem duas vezes mais chances de sofrer bullying do que o grupo controle. O estudo também identificou que os mais jovens possuem maior suscetibilidade de serem atacados por causa de sua condição.

Segundo Shu (2020), o bullying por alergia alimentar tem aumentado na medida em que aumentaram os casos de alergias em crianças e tornou-se um sério problema em escolas americanas. Cerca de um terço das crianças alérgicas em idade escolar são particularmente mais vulneráveis a sofrer bullying que seus pares (BECKER, 2013). Atitudes como ameaçar e forçar a ingestão de alimentos ou mesmo contaminar de maneira sub-reptícia o lanche de outro aluno, esfregar o alérgeno nos seus objetos são formas de bullying contra quem sofre de alergia alimentar. O assédio moral é uma das principais fontes de sofrimento para crianças nessas condições (FENG, 2018). O que diferencia o bullying por alergia alimentar do bullying comum é o componente físico. Crianças alérgicas são frequentemente vítimas de bullying diretamente com o alimento aos quais são alérgicas (SHU, 2020).

De acordo com Fong et al. (2017), na Austrália, a alergia alimentar afeta 1 a cada 12 crianças, com crescente aumento dos casos e significativa diminuição da qualidade de vida dos indivíduos alérgicos, principalmente crianças e adolescentes por suas interações, que em vários momentos precisam revelar sua condição particular no ambiente escolar.

\section{CONCLUSÃO}

No decorrer deste artigo buscou-se dissertar sobre convivência escolar e convivência ética, bem como, a importância de promover relações sociais cooperativas, solidárias e não excludentes entre adolescentes e jovens em contraponto ao bullying, principalmente quando os alvos são jovens acometidos por alguma alergia alimentar, que coloca-os em maior fragilidade, sendo mais propensos a receberem intimidações. 
Foi possível identificar que há um aumento na incidência do bullying em crianças e jovens com alergia alimentar, isso foi constatado, principalmente, em estudos internacionais, visto que o Brasil carece de pesquisas relacionadas ao tema. Os estudos confirmaram que a vitimização por bullying é uma experiência comum em pacientes alérgicos a alimentos, mais além, mostraram que é um problema universal e pelo fato de a maior parte da literatura sobre o tema ser internacional, isso ainda deve ser explorado no contexto brasileiro.

É preciso lançar um olhar mais atento sobre as possíveis ocorrências de bullying em crianças e jovens com alergia alimentar, dentro do ambiente escolar. Pois, o bullying têm um impacto emocional significativo em um indivíduo que já está fragilizado pela sua condição de saúde, pelo medo de ingerir alguma substância que vá lhe fazer mal.

A escola como um ambiente de convivência, deve estimular o respeito ao diferente. Nesse caso o aluno que precisa comer alimentos diferentes, talvez até utilizar um espaço diferente dos demais, mas, apesar disso, deve permanecer integrado com o grupo. A educação baseada em valores é um ponto chave para o enfrentamento de situações conflitantes, como o bullying contra jovens com alergia alimentar. É preciso investir na formação moral de nossos jovens (TOGNETTA, 2013). A escola tem total responsabilidade na qualidade das relações entre os alunos e deve buscar desenvolver projetos que estimulem a reciprocidade, o respeito e a empatia, que são fundamentais para um clima escolar positivo, visto que os impactos nas relações sociais, muitas vezes, podem ser mais significativos que a própria condição clínica.

Uma intervenção eficaz depende do diálogo entre pais e escola (SHEMESH, 2013; FENG, 2018), que devem estar preparadas para lidar com esse risco quando ele estiver presente (MURARO et al., 2014). É preciso permitir aos alunos expressem o que sentem e o que pensam, mediados por professores que entendam do desenvolvimento humano, pois os alunos não são meros expectadores que aguardam pelas nossas ações, eles devem ser atuantes (TOGNETTA, 2013). Buscar conhecimento e conscientização sobre o tema alergia alimentar e bullying e seus impactos na educação, comportamento e desempenho dos alunos é extremamente importante para os pais, alunos e escola (SHU, 2020). 
Crianças alérgicas a alimentos devem ser incluídas na categoria de alunos com alto risco de bullying.

A falta de conscientização e a escassez de estudos sobre esse tema revela que estamos na ponta de um iceberg e temos um vasto campo de estudo para explorar, assim como, não podemos nos furtar à vontade de lutar pela inclusão de alunos com alergias alimentares. 


\section{REFERÊNCIAS}

Andrade, d. C. M. De. Gestão do cuidado seguro da criança alérgica ao leite: a saúde do escolar e suas perspectivas. Research, society and development, v.9, n.04, $2020 . \quad$ Disponível em: https://www.rsdjournal.org/index.php/rsd/article/view/2899/2167. Acesso em: 16 jul. 2021.

Araújo, u. F. O ambiente escolar cooperativo e a construção do juízo moral infantil: sete anos de estudo longitudinal. Rev. Online bibl. Prof. Joel martins, campinas, sp, v.2, n.2, p.1-12, fev. 2001.

Asbai, associação brasileira de alergia alimentar. Disponível em: http://www.asbai.org.br/secao.asp?s=81\&id=306. Acesso em 29 jul. 2019.

Asbai, associação brasileira de alergia alimentar. Consenso brasileiro sobre alergia alimentar: 2018 parte 1 etiopatogenia, clínica e diagnóstico. Documento conjunto elaborado pela sociedade brasileira de pediatria e associação brasileira de alergia e imunologia. Jan.-mar. 2018, vol.2, núm.1. Disponível em:

http://aaai-asbai.org.br/detalhe_artigo.asp?id=851. Acesso em: 23 jul. 2021.

Becker, e. Food allergy bullying, how to protect your child from harassment. Jan. 2013. Disponível em: https://www.foodallergyawareness.org/media/education/bullyingfood\%20allergy\%20bullying_decjan2013_living\%20without\%20magazine.pdf. Acesso em: 22 jul. 2021.

Bozza, t. C. L. O uso da tecnologia nos tempos atuais: análise de programas de intervenção escolar na prevenção e redução da agressão virtual. Dissertação de mestrado. Setor de pós-graduação em educação. Unicamp, campinas (sp), 2016.

Cabral, a. Alergia alimentar: mitos e realidade. Sociedade portuguesa de alergologia 2019.2 Dediátrica. em: http://www.spaponline.pt/content_detail.php?97. Acesso em: 16 jul. 2021.

Feng, c. Kim, jean-hyoun. Beyond avoidance: the psychosocial impact of food alergies. Clinical reviews in allergy \& immunology. 57:74-82. 2018. Disponível em: https://link.springer.com/article/10.1007/s12016-018-8708-x. Acesso em: 22 jul. 2021.

Fnde, (fundo nacional de desenvolvimento da educação). Caderno de referência sobre alimentação escolar para estudantes com necessidades alimentares especiais / programa nacional de alimentação escolar. Brasília: fnde, 2016. 65 p. Disponível em:

http://www.fnde.gov.br/index.php/programas/pnae/pnae-area-gestores/pnaemanuais-cartilhas/item/10532-caderno-de-refer\%c3\%aanciaalimenta\%c3\%a7\%c3\%a3o-escolar-para-estudantes-com-necessidadesalimentares-especiais. Acesso em: 06 jul. 2021. 
Fong, a. T.; katelaris, c. H.; wainstein, b. Bullying and quality of life in children and adolescents with food allergy. Journal of paediatrics and child health, 2017. Disponível em: https://onlinelibrary.wiley.com/doi/abs/10.1111/jpc.13570. Acesso em: 23 jul. 2021.

Frick, I. T. Prevenção e contenção do bullying escolar: ações teóricas e governamentais no brasil e na espanha. Curitiba: crv, 2019.

La taille, y. De. Moral e ética: uma leitura psicológica. Rev. Psicologia: teoria e pesquisa, v. 26, n. Especial, p. 105-114, 2010.

Lieberman, j. A. Et al. Bullying among pediatric patients whit food allergy. Annals of

Allergy, asthma \& immunology v. 105, n. 4, 2010. Disponível em:

https://doi.org/10.1016/j.anai.2010.07.011. Acesso em: 29 jul. 2021.

Lin, a.; sharma, h. P. Teasing and bullying among adolescents with food allergy. J. Allergy clin. Immunol. Fev. 2014. Disponível em:

https://www.jacionline.org/action/showpdf?pii=s0091-6749\%2813\%2902924-2.

Acesso em: 23 jul. 2021.

Menin, m. S. De s. Et al. Projetos bem-sucedidos em educação em valores sociomorais: contribuições para o cotidiano da escola. Revista de educação puccampinas, campinas, v. 22, n. 1, p. 1-17, jan./abr., 2017.

Muraro, a. Et al. Comparison of bullying of food-allergic versus healthy schoolchildren in italy. J. Allergy clin. Immunol. V. 134, p. 749, 2014. Disponível em:

https://www.jacionline.org/article/s0091-6749(14)00807-0/fulltext. Acesso em: 01 ago. 2021.

Olweus, d. School bullying: development and some important challenges. Annu. Rev. Clin. Psychol. V. 9, p. 751-780, 2013. Disponível em: https://www.annualreviews.org/doi/10.1146/annurev-clinpsy-050212-185516.

Acesso em: 02 ago. 2021.

Piaget, j. O juízo moral na criança. São paulo: summus, 1994(1932).

Pinheiro, a. C. Et al. Estratégias de intervenção em ambiente escolar dirigidas às crianças com alergia alimentar. Rev. De ciências da saúde da esscvp. Lisboa, portugal, v. 12, nov. 2020. Disponível em:

http://comum.rcaap.pt/bitstream/10400.26/34116/1/salutis\%20scientia\%2012\%20 2\%203.pdf. Acesso em: 02 ago. 2021.

Sabra, a. Manual de alergia alimentar. $3^{a}$ ed. Rio de janeiro: rubio, 2015. E-book. Disponível em:

https://books.google.com.br/books?hl=pt-

br\&Ir=\&id=lcnbbqaaqbaj\&oi=fnd\&pg=pa1\&dq=alergia+alimentar+na+escola\&ots= xrnv-fgkbh\&sig=y6lf7fexs- 
9ei6eu5kkrowzd0dy\#v=onepage\&q=alergia\%20alimentar\%20na\%20escola\&f=fal se. Acesso em 02 ago. 2021.

Santos, e. S. Dos. Andrade, h. L. S. De. Reações adversas aos alimentos e implicações no ambiente escolar: contextualização com o movimento social "põe no rótulo". lii seminário de tecnologias aplicadas em educação e saúde (staes), 2017. Anais do seminário tecnologias aplicadas a educação e saúde. Uneb departamento de educação, 2017. Disponível em:

https://www.revistas.uneb.br/index.php/staes/article/view/3833. Acesso em: 12 jun. 2021.

Sarinho, e. S., lins, m. G. Severe forms of food allergy. Jornal de pediatria, rio de janeiro, v. 93, s. 1, p. 53-59, nov./dez. 2017. Disponível em:

https://www.sciencedirect.com/science/article/pii/s0021755717304230?via\%3dih ub. Acesso em 08 jun. 2021.

Sevinç, e; çetin, f. H.; cos,kun b. D. Psychopathology, quality of life, and related factors in children with celiacdisease. Jornal de pediatria, rio de janeiro, v. 93, n. 3, p. 267-273, mai./jun., 2017. Disponível em: https://jped.elsevier.es/ptpsychopathology-quality-life-related-factors-articulo-

s2255553616301495?referer=buscador. Acesso em: 08 jun. 2021.

Shemesh, e. Et al. Child and parental reports of bullying in a consecutive sample of children with food allergy. Pediatrics, v. 131, p. 10-17, 2013. Disponível em:

https://www.ncbi.nlm.nih.gov/pmc/articles/pmc3529950/. Acesso em: 22/07/2021. Doi: https://doi.org/10.1542/peds.2012-1180.

Shu, d. M. Food allergy bullying as disability harassment: holding schools accountable. Aals, section on law, medicine, and health care, 2020. Disponível em:

https://papers.ssrn.com/sol3/papers.cfm?abstract_id=3563349. Acesso em: 22 jul. 2021.

Silva, a. B. Bullying: mentes perigosas nas escolas. Rio de janeiro: objetiva, 2010.

Silva, I. A. Et al. Adult food allergy prevalence: reducing questionnaire bias. Int arch allergy immunol. V. 171, n. 3-4, p. 261-264, jan. 2016. Disponível em: https://pubmed.ncbi.nlm.nih.gov/28049191/. Acesso em: 23 jul. 2021.

Stelko-pereira, a. C.; williams, I. C. A. Reflexões sobre o conceito de violência escolar e a busca por uma definição abrangente. Temas em psicologia, ribeirão preto, v. 18, n. 1, p. 45-55, jun. 2010. Disponível em:

http://www.redalyc.org/articulo.oa?id=513751435005. Acesso em: 02 ago. 2021.

Tognetta, I. R. P. Rosário, p. Bullying: dimensões psicológicas no desenvolvimento moral. Estudos em avaliação educacional, são paulo, v. 24, n. 56, p. 106-137, set./dez. 2013. Disponível em: http://hdl.handle.net/11449/125165. Acesso em: 04 ago. 2021. 
Tognetta, I. R. P.; vinha, t. P. Estamos em conflito, eu, comigo e com você: uma reflexão sobre o bullying e suas causas afetivas. Escola, conflitos e violências. Santa maria, 2008. Disponível em:

http://www.mpsp.mp.br/portal/page/portal/educacao/doutrina/bullying\%20estamo s\%20em\%20conflito.pdf. Acesso em: 04/ago. 2021.

Tognetta, I. R. P.; vinha, t. P.; avilés, j. M. M. Bullying e a negação da convivência ética: quando a violência é um valor. International journal of developmental and educational psychology, badajoz, españa, v. 7, n. 1, 2014, p. 315-322. Disponível em: https://www.redalyc.org/pdf/3498/349851791032.pdf. Acesso em: 04 ago. 2021.

Vinha, t. P. Escola também é responsável pelo desenvolvimento de valores morais. Nova escola, 13 dez. 2018. Disponível em:

https://novaescola.org.br/conteudo/14567/escola-tambem-e-responsavel-pelodesenvolvimento-de-valores-morais. Acesso em: 21 abr. 2021.

Vinha, t p.; morais, a. De; moro, a. Manual de orientação para a aplicação dos questionários que avaliam o clima escolar. Campinas, sp: fe/unicamp, 2017.

Vinha, t. P. Et al. O clima escolar e a convivência respeitosa nas instituições educativas. Est. Aval. Educ., são paulo, v. 27, n. 64, p. 96-127, jan./abr. 2016.

Zechi, j. A. M. Educação em valores: solução para a violência e indisciplina na escola. 2014. 279 f. Tese (doutorado em educação) - programa de pós-graduação em educação, faculdade de ciências e tecnologia, presidente prudente, 2014. 